\title{
Rhodium-Catalyzed Asymmetric Dearomatization of Naphthols with Alkynes
}

\section{Category}

Metal-Catalyzed Asymmetric

Synthesis and

Stereoselective

Reactions

\section{Key words}

dearomatization

C-H bond activation

rhodium<smiles>Oc1ccc2ccccc2c1-c1ccccc1</smiles>
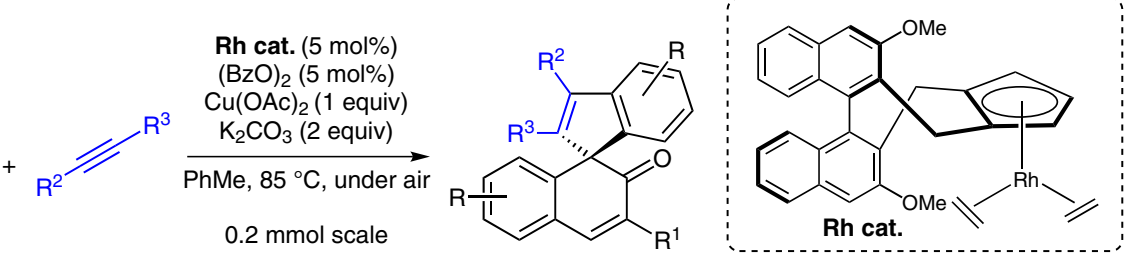

Selected examples: $(\mathrm{rr}=$ alkene regioselectivity)

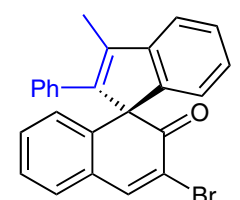

$81 \%$ yield

$90 \%$ ee

$\mathrm{rr}=17: 1$

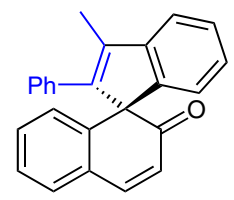

$38 \%$ yield

$78 \%$ ee $\mathrm{rr}=11: 1$

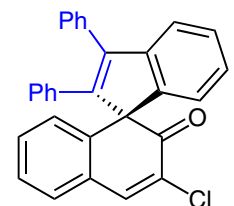
$85 \%$ yield [3.2 $\mathrm{mmol}$ scale]

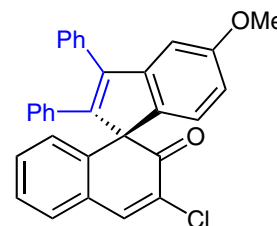

$82 \%$ yield $80 \%$ ee

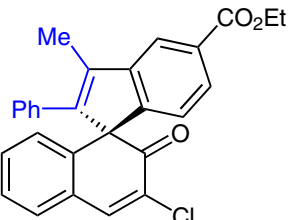

$72 \%$ yield $82 \%$ ee

Proposed mechanism:

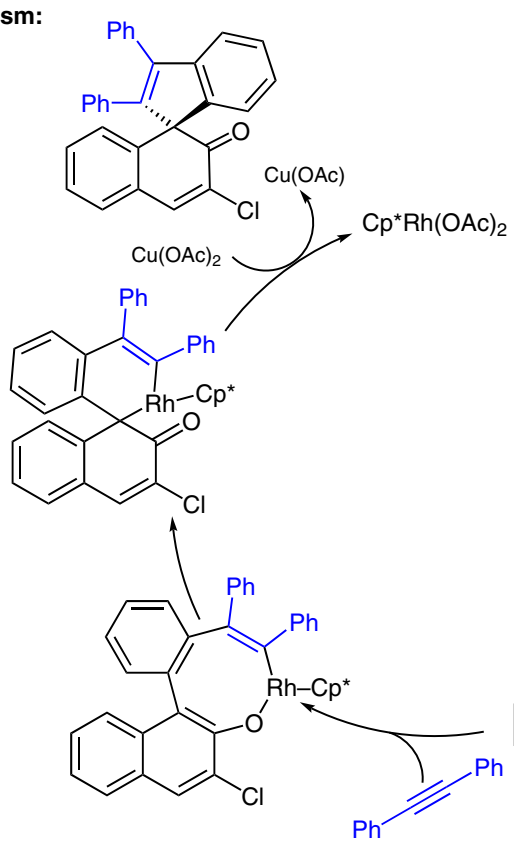

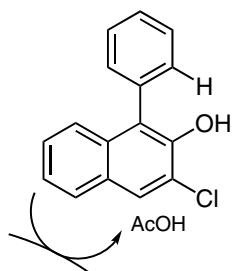<smiles>Cc1ccc(I)cc1</smiles>

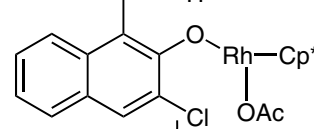

Significance: Recent efforts have been extended towards the development of asymmetric $\mathrm{C}-\mathrm{H}$ functionalization reactions. The authors report an asymmetric version of the previously known metal-catalyzed dearomatization of phenols.

SYNFACTS Contributors: Mark Lautens, Thomas Johnson Synfacts 2015, 11(7), $0721 \quad$ Published online: 17.06.2015 DOI: 10.1055/s-0034-1380947; Reg-No.: L06315SF
Comment: Twenty-six dearomatized products were synthesized in moderate to high enantioselectivity by using a chiral ligand recently invented by Cramer. The use of unsymmetrical alkynes leads to regioisomeric alkene mixtures in greater than 7:1 selectivity. A primary deuterium kinetic isotope effect indicates that $\mathrm{C}-\mathrm{H}$ bond cleavage is most likely the rate-determining step. 